\title{
Reading Fluency Techniques from the Bottom-up: A Grounded Theory
}

\author{
Seyyed Ali Ostovar-Namaghi (Corresponding author) \\ University of Shahrood, Iran \\ E-mail: saostovarnamaghi@yahoo.com \\ Seyyedeh Mobina Hosseini \\ University of Shahrood, Iran \\ Shabnam Norouzi \\ University of Shahrood, Iran
}

Received: 07-01-2015

Published: 01-09- 2015
Accepted: 09-03- 2015

doi:10.7575/aiac.ijalel.v.4n.5p.29
Advance Access Published: April 2015

URL: http://dx.doi.org/10.7575/aiac.ijalel.v.4n.5p.29

\begin{abstract}
In many EFL contexts, including language education milieu in Iran, reading fluency is usually taken for granted since language education in public high schools mainly focuses on reading comprehension. Taking the detrimental effect of fluency deficiency into account, some practitioners foreground reading fluency and try to develop it early on. To give voice to their theories of practice, this qualitative study interviewed teachers who were willing to share their experience with the researchers. In line with grounded theory, the iterative process of data collection and analysis continued until the conceptualization of fluency development techniques was saturated. The techniques emerged are conducive to fluency development and as such the findings have clear implications for practitioners and policy makers nation-wide.
\end{abstract}

Keywords: reading theory, reading fluency, reading techniques

\section{Introduction}

Despite the fact that reading comprehension is the focal point of language education in public high schools of Iran, students' achievement fall short of teachers' expectations. The reason is that teachers force students to comprehend texts the phonological decoding of which is next to impossible for them. That is, fluency deficiency attracts their whole attention towards form and this leaves no room in their working memory for meaning. Fluency deficiency is an offshoot of the high-stake nation-wide university entrance exam which suffers from construct underrepresentation (OstovarNamaghi, 2011). That is, it ignores many aspects of language proficiency including listening, speaking, writing, pronunciation and many other important aspects and focuses exclusively on reading comprehension, grammar, and vocabulary. Knowing that reading fluency is not measured in the university entrance exam, teachers and learners deliberately ignore it. Believing that fluency deficiency has overshadowed the mastery of other aspects such as reading comprehension, the researchers hypothesize that developing reading fluency has a significant effect on students' reading comprehension.

\section{Literature Review}

Fluency can be conceptualized in different ways. But an effective way is to have a look at what fluent readers do. Wood, Flowers and Grigorenko (2001) believe that fluent readers predict what comes next in the text since prediction sharpens their reaction time and this in turn boosts automaticity. Moreover Grabe and Stoller (2002) suggest that fluent reading is contingent upon: (1) automatic word recognition; and (2) fast and automatic syntactic parsing. Therefore, fluency is thought to consist of both accuracy and automaticity in word recognition as well as the appropriate use of prosodic and syntactic knowledge for better comprehension of text (Grabe, 2004).

According to the automaticity theory, deriving meaning from printed texts entails decoding and comprehension; the former refers to a process in which printed words are translated into spoken words (Samuels, 1994), and the latter entails deriving meaning from spoken forms. Rasinski (2004) argued that there are three dimensions in reading fluency: accuracy in word decoding, automatic processing, and prosodic reading (p. 46). Automaticity is part and parcel of fluency. It involves rapid identification of letters, letter patterns and individual words correctly and instantaneously. Fluency encompasses an integration of automatic word recognition and features stretching beyond words to phrase and sentence level.

Successful reading involves automatic word identification and comprehension; therefore failure in one gives rise to failure in the other (Lyon, 1995). The reason is that when when the readers' attention is devoted to identifying words with difficulty, he reads slowly and cannot attend form and as such comprehension fails because low speed overloads his or her short-term memory. The teachers' instructional strategy can alleviate or exacerbate this problem. To help such 
challenging readers, the teacher should focus on the alphabetic approach rather than the whole word approach (Chall, 1996).

Two theories clearly show that efficient reading is a function of reading fluency: Automaticity theory (Samuels 1994) and verbal efficiency theory (Perfetti, 1988). Both theories require that form be processed automatically so that the limited attention capacity be devoted to meaning (Benjafield, 1997). Automaticity theory posits that translating texts to spoken form should be processed subconsciously so that conscious attention is allocated to comprehension. Verbal efficiency theory goes beyond automatic word identification to automatically resolving anaphors, and activating relevant background schemas through deliberate practice. It is theorized that spontaneous and automatic processing of lower-level subcomponent reading processes frees up our limited attention capacity for higher-level subcomponents of reading.

Challenging readers fail to comprehend texts although they are able to recognize words accurately since they spend excessive time in the process of word identification. On the other hand, efficient readers are able to recognize words accurately and rapidly, and as such they have greater capacity for attention leading to comprehending a text. Thus reading instruction should involve challenging readers in deliberate practice, i.e., a form of practice in which the learner is aware of his weaknesses and monitors the effect of practice on resolving his deficiencies. As students acquire word identification skills and an awareness of the syntactic structure of sentences, they increase the speed at which they can process text until it no longer competes with comprehension but rather facilitates it.

Taking the foregoing theoretical insights into account, practitioners have devised instructional techniques to develop automaticity and fluency. That is they have developed instructional strategies that aim at: (1) effortless identification of words; and (2) effortless processing of longer stretches such as phrases, sentences and text. Review of previous studies is indicative of five main fluency development strategies: repeated reading (RR) and extensive reading (ER); assisted reading (AR), segmentation, and music

RR was devised by Samuels (1979) to translate automaticity theory (LaBerge \& Samuels, 1974) into practice. Indeed, the research findings suggest that re-reading passages increases students' oral reading rates and accuracy (Carver \& Hoffman, 1981). In addition, practice effects from re-reading a passage are carried over to new, unpracticed passages in terms of reading rate and accuracy (Carver \& Hoffman, 1981).

ER is another effective technique of fluency development. Samuels (2006) and Blevins (2005) claimed that ER is an effective approach to improving learners' reading fluency. The theoretical frameworks supporting ER include input hypothesis (Krashen, 1985, p. 2), and pleasure hypothesis (Krashen, 2004). Krashen's (2004) pleasure hypothesis proposed that pedagogical activities which help language acquisition are those that are enjoyable, "but enjoyment does not guarantee language acquisition" (p. 28). Research into fluency has shown that assisted reading (Rasinski \& Hoffman, 2003) can also significantly improve reading fluency.

Another technique of reading fluency is text segmentation. Grouping words into meaningful chunks is a fundamental process for fluent reading (Yamashita, 2012). In this study he investigated the relationship between chunking and second language (L2) reading fluency. The results show that the difficulty of chunking a text negatively affects comprehension and smoothness for the intermediate learners, while the advanced learners were able to overcome chunking difficulty. Although the negative effects of chunking difficulty were observed, the positive effects of assisting chunking were not clearly detected, which was interpreted as suggesting that the relationship between chunking and reading needs to be considered in light of the complex interplay between text difficulty and different aspects of reading.

Finally some scholars have focused on using songs and music as effective fluency development techniques. For instance, some researchers have recommended using songs to enhance fluency (Rasinski, 2006; Sample, 2005). Patel and Laud (2007) evaluated the use of songs with lyrics to increase the reading fluency rates of three middle school students. They concluded that using song lyrics may be a superior way to strengthen fluency. As for the use of music, Sample (2005) proposes that adolescents are motivated by music and would enjoy using class time to learn the words to popular songs with high-frequency words and patterns.

Although the effect of fluency and automaticity on reading comprehension should be acknowledged, it cannot be taken for granted. That is, although theories of automaticity and fluency are promising for developing learners' reading comprehension, practitioners cannot use these insights in practice unless they are substantiated by some empirical findings. Having tested the hypothetical effect of automaticity and fluency on reading comprehension, researchers present the field with the following empirical findings:

- fluency instruction resulted in improvements in students' reading fluency and overall reading achievement (Kuhn \& Stahl, 2000; Rasinski \& Hoffman, 2003);

- $\quad$ reading fluency was related to text understanding, to reading comprehension (Rasinski \& Hoffman, 2003);

- $\quad$ RR had a positive effect on readers' vocabulary development (Koskinen \& Blum, 1984);

- RR improved the readers' ability to fluently and accurately read books of increasing difficulty (Blum, Koskinen, Tennant, Parker, Straub, \& Curry, 1995);

- $\quad$ silent reading rates increased significantly even at the seventh reading within the practiced passages, and that there was no leveling off of reading rate increases (Taguchi ,1997);

- the ten-week RR program significantly improved the nine participants' reading rates from a pre-test reading passage to a post-test reading passage (a different passage) (Taguchi \& Gorsuch ,2002); 
- training in word recognition developed the L2 readers' speed in isolated words recognition skills. There was, however, no transfer effect of the word recognition training on reading speed or comprehension of the connected test passages (Fukkink, Hulstijn, \& Simis,2005);

- ER gives the learner the chance to encounter the same word many times over and as such increases sight vocabulary (Renandya \& Jacobs, 2002; Samuels, 2006);

- providing learners with repeated exposure to texts built their reading self-confidence and helps them avoid frustrations such as lack of comprehension arising from slower reading (Nuttall, 1996).

\section{Purpose of the Study}

A synthetic summary of the empirical findings clearly shows that: (1) reading fluency is a pre-requisite of reading comprehension; (2) fluency studies are mainly theory-first, i.e., they aim at improving practice and as such they take practitioners as the consumers of research findings; (3) practitioners' voice is totally missing in the findings. Previous studies have ignored the fact that conceptualization of practice can also change aspects of theories. To fill in this gap, this qualitative study aims at exploring and conceptualizing language teachers' perspectives concerning fluency development. More specifically, it aims at answering the research question, "What techniques do language teachers use to develop EFL learners' reading fluency?

\section{Research Method}

\subsection{Participants}

In line with grounded theory, this study sampled theoretically-relevant concepts from interview data. It started with a number of experienced teachers who were willing to share their experience with the researcher. Based on purposive sampling, the number of participants was not fixed, it was determined based on theoretical saturation, a point at which data collection and analysis no longer yields any useful information. Participants were taken from different private institutes in Behshahr, a city in Mazandaran Province. All of them had received either their bachelors' degree or masters' degree in TEFL. Having explained the purpose and rationale of the study and having sought participant consent, the researchers chose six male and five female English teachers who had more than five years of teaching experience.

\subsection{Data Collection and Analysis}

Since the study aimed at theorizing practitioners perspectives concerning techniques of reading fluency, we began the interview with a very general question to elicit information on the techniques they use to develop learners' reading fluency. In line with the principles of grounded theory, the interviews were all audio-recorded to be transcribed verbatim and meticulously analyzed soon after the interviews through open coding, axial coding and selective coding. The total time for interviewing each one of the participants averaged 20 minutes, with a minimum of 10 minutes and a maximum of 35 minutes. In line with the ethics of qualitative research, participants' real names were not identified in the final report of the findings.

\section{Results}

This study aimed to explore the techniques EFL teachers used in developing reading fluency in private institutes of Iran. The researchers used grounded theory to collect and analyze qualitative data. Analysis revealed that the participants used six different techniques: Repeated listening, teaching challenging words and phrases, choral and individual repetition, repeated reading, singing songs and pair and group work. What follows aims at elaborating these techniques by grounding them on the participants' perspectives.

\subsection{Repeated Listening}

While in most of the research, repeated reading is encouraged, the participants of this study suggested repeated listening as a more authentic source for repetition. Repeated listening is superior to teacher repetition because of the authenticity of the material. One of the participants explains how she starts teaching reading with this technique:

In order to make students fluent readers, first of all I expose them to correct pronunciation. If the reading passage includes a recorded tape, the first thing to do is listening to that tape, so that the students hear native speakers' voice. The tape should be played several times in the class, so that students totally get acquainted with the native speakers'voice. Due to the limited time of classroom, the students are asked to listen to the tape several more times at home. Then for the next session, the first thing to do is listening to the previous reading passage before reading a new one.

Knowing the correct intonation and stress pattern of words or sentences will definitely help students to become fluent readers. Listening to the authentic material repeatedly prior to reading the passage is a technique used by another participant who explains:

Before opening the book to the reading page, I ask students just to listen to the $C D$, and focus on intonation of new words and sentences. After listening to the tape for the first time, I ask them to open their books and read the text silently and also underline the words which they cannot pronounce correctly. After this task, I replay the CD two or three times and I ask students to listen carefully to the text, especially to the underlined words.

Another participant highlighted the importance of repeated listening and explained: 
Common classroom listening activities usually take place in a way that students listen to the tape once or twice. But in my opinion, repeated listening is one of the most important techniques and it should be used more than three or four times in the class. The reason for the importance of repeated listening is that students need to be familiar with the correct pronunciation, intonation, stress pattern of words and sentences. For this reason the most authentic material is definitely the ones orally recorded by native speakers of English.

\subsection{Teaching challenging phrases and words}

The importance of automatic word recognition would seem to have practical implications for building fluency. Studies in which teachers had students practice reading lists of words that they were to encounter in connected texts consistently resulted in increased fluency. One of the participants explains the importance of teaching new words and phrases before making students read the passage:

Before teaching the reading passage, I find out those phrases which contain new words that students may have problem pronouncing them. I highlight the key words and even technical vocabulary in the reading passage and then write them down for further practice. Of course it is known that students should read phrases first and they should be taught how to chunk sentences in a group of words. But sometimes there may be some difficult or technical words in the passage that will frustrate students.

Being familiar with the new vocabulary, idioms and collocations and knowing their meaning helps students not only to understand the text, but also to read it more fluently without any hesitation. When there are lots of new vocabularies and idioms in reading text, students are not willing to read. In elaborating this point, one of the participants explains:

I always highlight idioms and collocations which are challenging for my students. Before teaching the passage, I prepare a glossary of challenging phrases and ask students either to practice them at home or we work it together in the classroom. We repeat these idioms or collocations again and again so that students get the correct pronunciation, meaning, and intonation.

Another participant explains:

Most of the time new words are challenging for students. In order to provide a stress free environment for learning reading passage, I write the new vocabularies and collocations on the board and practice them with my students. Then I play the CD and ask students to focus, whenever it comes to the new words, I stop the CD and ask students to repeat what they've heard. Of course I don't ask them to repeat the new word in isolation; rather it should appear in a phrase. So the phrase in which the new words appear is practiced several times.

As for the importance of teaching phrases which contain new vocabulary, another participant explains:

We should have in mind that a prerequisite of reading fluency is that learners need to see words in groups of three-, four-, and five-word units. We should teach students rather than looking down and seeing a passage as hundreds of disconnected, individual words, they need to see and read words in larger phrasal units. To this end, we should teach students "chunking" which means grouping words into a unit. For example in reading a passage when we encounter a two-word-verb, we have to make sure that students see it as a single unit not as two separate words and make students repeat the phrase as one single unit.

\subsection{Choral and Individual Repetition}

Immediately after the presentation of new materials, the students need a controlled practice stage in which they have the chance to focus exclusively on the new language item and familiarize themselves with it. This can be done through repetition drills - the teacher simply says a sentence containing the target structure (or even just the lexical item being taught) and the students repeat it. This can be done either chorally or individually. One of the participants explains how he uses this technique in the classroom:

After teaching the passage completely, we should focus on practice and repetition. Before production, we should be sure that students have the correct perception. When students listen to the $C D$, we can ask them to repeat it line by line or chunk by chunk. One more time, I read the passage and ask them to repeat after me. After chorally repeating the sentences after the $C D$, I ask one of the strong students to read the passage and ask others to follow her. For individual repetition, I play the CD again and after pausing on a certain line; I ask one of the students to repeat the sentence.

In order to ask students to repeat the passage, text length should be controlled. Controlling text length may be beneficial for students who have difficulty with reading accuracy as it may encourage them to focus on the words for a longer period of time. Another participant elaborates this point and explains the importance of chunking while students are chorally or individually repeating:

Chunking is of great importance in repetition. When students listened to the CD two or more times, I ask them to repeat the text chunk by chunk, especially for lower level students who have trouble repeating longer texts. While they are chorally repeating the text, I find those students who are better in repetition. Then I ask them to act as the class leader. The leader then reads the text and the rest of the class repeat after her. In this way, students are motivated to read more effectively. 


\subsection{Repeated Reading}

Repeated reading is one of the well-known techniques for improving reading fluency. It consists of re-reading a passage several times until the reader reads it with ease. This technique is used by all participants of the study. One of them explains:

Repeated reading can be used along with all the previous techniques I mentioned. After practicing the text through listening, choral or individual repetition, I ask a number of students to read the text out loud. Depending on the time at my disposal, two or three students read the text. With this technique I can be sure to what extent students read the text fluently.

Another participant explains:

At the end of the class, I read the text myself one more time and then I ask students to read it one by one. If the text is short then all students have a chance to read, but in the case of long difficult texts, I try to provide the opportunity at least for half of the class to read.

\subsection{Singing Songs}

Songs and music are considered as a great authentic source for reading fluency development. Listening to songs familiarize students with the correct pronunciation and intonation. One of the participants who use this technique in the class explains:

Another technique which has a remarkable effect on reading fluency is listening to songs. Since students (especially lower level students) enjoy listening to music, this technique is really helpful. We can play a song in the classroom and in the meantime we can give the lyrics to students and encourage them to follow through and sing while listening.

Another participant claims that students really welcome this technique. To substantiate his view, he explains:

The first page of each unit consists of a song. I play the song for students several times. After making sure that they've learned the intonation and pronunciation, I ask them to sing the song all together. Then I play the music and ask the students to sing as a group or individually.

Another participant explains the importance of songs and suggests using songs which have interesting and functional words:

Songs are of great importance in making students fluent readers. First of all, students love listening and singing songs, they enjoy it. Second, songs have the correct phrasing, intonation, stress patterns. In my classes I usually choose those songs which contain interesting and functional words, i.e., words which are useful in communication, have appropriate lyrics and have a medium rate with clear phrasing in which words can be understood. I want students to listen to the songs while looking at the lyrics. After listening to the songs repeatedly, I ask them to sing the song together. We sing it several times, and even for the next session I want them to sing it one more time.

\subsection{Pair work and Group work}

This technique will help students to speak and communicate in their group with their friends. One of the participants explains:

We cannot say that reading comprehension is separate from reading fluency. In this technique, both comprehension and fluency can be practiced. to this end, I divide the students into several groups and I give them a text that was practiced before. Then I ask them to practice it inside the groups and after understanding the text they have to choose a title for the selected text. After that, one of the students in the group should read the text aloud. If they have any pronunciation problems, I correct them smoothly.

Another participant explains:

Sometimes I divide the class in to groups of four, and I ask the students to work together. Then one of them reads the text fluently. In order to make it a little competitive, those who read more fluently are encouraged.

One of the participants explains the importance of pair and group work and says:

Pair work and group work give the students far more chances to speak English in the classroom. Students participate in the lesson much more actively because they are involved in talking to their friends, exchanging opinions, practicing new structures more than listening to their teacher talking. To achieve this goal, I divide students into groups of four and give them the passage and I want them to practice it inside their groups and explain the content of the passage to each other. Then one of them voluntarily reads the passage fluently.

\section{Conclusion and Implications}

Having reviewed the empirical findings related to reading fluency and how it affects reading comprehension, the researchers found that the previous studies, as their common goal, aimed at improving the practitioners' work. That is, they subconsciously inculcate the idea that the relationship between theory and practice is unilateral. This presupposition is deeply rooted in the applied science model of teacher education which takes teachers as the consumers of theoretical findings. Since language teaching is no longer in its infancy, practitioners have their own grounded theories, i.e., theories of practice. 
We strongly believe that conceptualization of teachers' perspectives, which reflect their theories of practice, yields an effect in the opposite direction, i.e., practice can modify aspects of theory. Along these lines, this qualitative study conceptualized practitioners' perspectives regarding techniques of fluency development and the results clearly show that teachers' practice is shaped by their experiential knowledge rather than the prescriptions and proscriptions of theorists and researchers. Moreover, if researchers and theorizers heed practitioners' perspectives, i.e., grounded theories, for sure they will modify their grand theories. As such, this study has clear implications for:

- language teachers since the results give them some practical techniques for reading fluency development;

- syllabus designers since the findings clearly show that they should not take fluency for granted and develop tasks, exercises, and drills that develop fluency along with tasks and exercises that develop reading comprehension;

- researchers since the conceptualization of teachers' perspectives concerning reading fluency clearly shows that data-first studies should be taken seriously since they complement theory-first studies; and

- theorists since this conceptualization of teachers' perspectives give them some hints to modify their grand theories of reading fluency.

\section{References}

Benjafield, J. (1997). Cognition. (2nd ed.). New Jersey: Prentice Hall.

Blevins, W. (2005). The importance of reading fluency and the English language learner. The Language Teacher, 29, $13-16$.

Blum, I., Koskinen, P. A., Tennant, N., Parker, E. M., Straub, M., \& Curry, C. (1995). Using audiotaped books to extend classroom literacy instruction into the homes of second-language learners. Journal of Reading Behavior, 27, 535-563.

Carver, R. P., \& Hoffman, J. V. (1981). The effect of practice through repeated reading on gain in reading ability using a computer-based instructional system. Reading Research Quarterly, 16, 374-390.

Chall, J. (1996). Learning to read: The great debate. Cambridge, MA: MIT.

Day, R. R., \& Bamford, J. (2002). Top ten principles for teaching extensive reading. Reading in a Foreign Language, $14,136-141$.

Dlugosz, D. W. (2000). Rethinking the role of reading in teaching a foreign language to young learners. English Language Teaching Journal, 54, 284-290.

Dowhower, S. L. (1987). Effects of repeated reading on second-grade transitional readers' fluency and comprehension. Reading Research Quarterly, 22, 389-406.

Fukkink, R. G., Hulstijn, J., \& Simis, A. (2005). Does training in second-language word recognition skills affect reading comprehension? An experimental study. Modern Language Journal, 89, 54-75.

Fleisher, L. S., Jenkins, J. R., \& Pany, D. (1979). Effects on poor readers' comprehension of training in rapid decoding. Reading Research Quarterly, 15, 30-48.

Grabe, W. (2004). Research on teaching reading. Annual Review of Applied Linguistics, 24, 44-69.

Grabe, W., \& Stoller, F. L. (2002). Teaching and researching reading. Harlow: Pearson Education.

Koskinen, P. S., \& Blum, I. H. (1984). Repeated oral reading and the acquisition of fluency. In J. Niles \& L. Harris (Eds.), Changing perspectives on research in reading/language processing and instruction. Thirty-third Yearbook of the National Reading Conference (pp. 183-187). Rochester, NY: National Reading Conference.

Kuhn, M.R., \& Stahl, S. A. (2000). Fluency: A review of developmental and remedial practices (CIERA Rep. No. 2008). Ann Arbor, MI: Center for the Improvement of Early Reading Achievement.

Krashen, S. D. (1985). The input hypothesis: Issues and implications. New York: Longman.

Krashen, S. D. (2004). The power of reading: Insights from the research (2nd ed.). Portsmouth, NH: Heinemann.

LaBerge, D., \& Samuels, S. J. (1974). Toward a theory of automatic information processing in reading. Cognitive Psychology, 6, 293-323.

Lyon, J. R. ( 1995). Towards a definition of dyslexia. Annals of Dyslexia, 45, 3-27.

Nuttall, C. (1996). Teaching reading skills in a foreign language. Oxford: Heinemann.

Ostovar-Namaghi, S. A. (2011). A comparative study of test tasks and target use tasks. Theory and Practice in Language Studies, 1(5), 525-529.

Perfetti, C. A. (1988). Verbal efficiency in reading ability. In M. Daneman, G. E. Mackinnon, \& T. G. Waller (Eds.), Reading research: Advances in theory and practice (Vol. 6; pp. 109-143). New York: Academic Press.

Patal, P. \& Laud, L. (2007). Using Songs to Strengthen Reading Fluency. Teaching Exceptional Children Plus (4)2, 2 17. 
Rasinski, T. V. (1995). Fast Start: A parental involvement reading program for primary grade students. In W. Linek \& E. Sturtevant (Eds.), Generations of Literacy. Seventeenth Yearbook of the College Reading Association (pp. 301312). Harrisonburg, VA: College Reading Association.

Rasinski, T. V. (2004). Creating fluent readers. Educational Leadership, 61, 46-51.

Rasinski, T. (2006). Reading fluency instruction: Moving beyond accuracy, automaticity, and prosody. The Reading Teacher, 59 (7). 704-6.

Renandya, W. A., \& Jacobs, G. M. (2002). Extensive reading: Why aren't we all doing it? In J. C. Richards \& W. A. Renandya (Eds.), Methodology in language teaching: An anthology of current practice (pp. 295-302). Cambridge: Cambridge University Press.

Rasinski, T. V., \& Hoffman, J. V. (2003). Theory and research into practice: Oral reading in the school literacy curriculum. Reading Research Quarterly, 38, 510-522.

Sample, K. J. (2005) Promoting fluency in adolescents with reading difficulties. Intervention in School and Clinic, 40 (4), 243-6.

Samuels, S. J. (1994). Toward a theory of automatic information processing in reading, revisited.

In R. B. Ruddell, M. R. Ruddell, and H. Singer (Eds.), Theoretical models and processes of reading (4th ed.) (pp. 816837). Newark, DE: International Reading Association.

Samuels, S. J. (2006). Reading fluency: Its past, present, and future. In T. V. Rasinski, C. Blachowicz, \& K. Lems (Eds.), Fluency instruction: Research-based best practices (pp. 7-20). New York: The Guilford Press.

Taguchi, E. (1997). The effects of repeated readings on the development of lower identification skills of FL readers. Reading in a Foreign Language, 11, 97-119.

Taguchi, E., \& Gorsuch, G. J. (2002). Transfer effects of repeated EFL reading on reading new passages: A preliminary investigation. Reading in a Foreign Language, 14(1), 43-65. Retrieved April 23, 2006, from http://www.nflrc.hawaii.edu/rfl/April2002/taguchi/taguchi.pdf

Wood, F. B., Flowers, L., \& Grigorinko, E. (2001). On the functional autonomy of neuroanatomy of fluency or why walking is just as important to reading as talking is. In M. Wolf (Ed.), Dyslexia, fluency and the brain Timonium, MD: York Press.

Yamashita, J. \& Ichikawa, Sh. (2012). Examining reading fluency in a foreign language: Effects of text segmentation on L2 readers. Reading in a Foreign Language,22(2), 263-283. 